\title{
Nebria germari Heer, 1837 - insight about the distribution and ecology of a climate-sensitive species of the Eastern Alps
}

\author{
Barbara Valle ${ }^{\ddagger} \S$, Roberto Ambrosini ${ }^{\S}$, Marco Caccianiga ${ }^{\S}$, Mauro Gobbi ${ }^{\ddagger}$ \\ ‡ MUSE-Science Museum, Trento, Italy \\ $\S$ University of Milan, Milan, Italy
}

Corresponding author: Mauro Gobbi (mauro.gobbi@muse.it)

Received: 11 Jun 2019 | Published: 12 Jun 2019

Citation: Valle B, Ambrosini R, Caccianiga M, Gobbi M (2019) Nebria germari Heer, 1837 - insight about the distribution and ecology of a climate-sensitive species of the Eastern Alps. ARPHA Conference Abstracts 2: e37074. https://doi.org/10.3897/aca.2.e37074

\begin{abstract}
Nebria germari (Coleoptera: Carabidae) is a cold-adapted species currently restricted to high altitude habitats of the Eastern Alps and exhibits fragmented distribution patterns suggesting refugial occurrence. It is a brachypterous species (thus with low dispersal ability) and it has nocturnal forage behaviour (mainly predating springtails and midges).

Since $N$. germari is an endemic and a climate-sensitive species, we performed a study aimed at describing the past distribution on the Dolomites (Italy), the ecology and the current population dynamic on debris-covered glaciers of this area where it is still abundant.

The past distribution was investigated by reviewing literature and analysing the labels of the specimens preserved in some Museum collections. We found that, until the second half of the last century, the lower altitudinal limit of this species was around $2000 \mathrm{~m}$ asl. Specifically, it was abundant in alpine grasslands on carbonate substrata (Carex firmadominated). Field data collected in the last ten years demonstrated the current extinction in this grassland type of the Southern Alps, with a consequent contraction of the distribution.
\end{abstract}


Currently, N. germari is still abundant in high altitude, north-faced, scree slopes with macroporal soil structure, in deep underground and on debris-covered glaciers due to its preference for cold temperatures (i.e. terrains with average annual temperature of ca. $0^{\circ} \mathrm{C}$ ).

Preliminary results obtained analysing, through the snow-free period, the larval, sub-adult and adult abundance patterns on debris-covered glaciers suggest that, in this kind of harsh habitat, $N$. germari is a spring rather than an autumn breeder as was documented in the last century for the populations found in high alpine prairies. In addition, the population size seems to decrease from the snowmelt to the beginning of the snow period and to increase with the percentage of coarse fraction of the terrain. Conversely, no significant relation was found between the population size and the abundance of preys (Collembola) and competitors (Araneae).

\section{Keywords}

Carabidae, Cold-adapted species, Debris-covered glaciers, Dolomites.

\section{Presenting author}

Barbara Valle

\section{Presented at}

19thECM poster

\section{Acknowledgements}

The research is co-financed by Provincia Autonoma di Trento, Parco Naturale Adamello Brenta and Parco Naturale Dolomiti d'Ampezzo. 